\title{
EVALUATION OF DRUG USE FOR RESPIRATORY PROBLEMS IN DEPOK, INDONESIA, BEFORE AND AFTER IMPLEMENTATION OF THE NATIONAL FORMULARY
}

\author{
REISE MANNINDA ${ }^{1}$, RETNOSARI ANDRAJATI ${ }^{2 *}$ \\ ${ }^{1}$ Department of Clinical Pharmacy, Faculty of Pharmacy, Universitas Pancasila, Jakarta 12640, Indonesia. ${ }^{2}$ Department of Pharmacy, \\ Faculty of Pharmacy, Universitas Indonesia, Depok 16424, Indonesia. Email: andrajati@farmasi.ui.ac.id
}

Received: 26 June 2018, Revised and Accepted: 28 September 2018 and 30 November 2018

\section{ABSTRACT}

Objective: The aim of this study was to compare the quantity and quality of drug utilization (DU) in patients with respiratory problems at a hospital in Indonesia before and after the implementation of the national formulary.

Methods: A cross-sectional retrospective study was conducted in 2013 and 2015 at the Depok Hospital in Indonesia. Prescriptions and data from patients were recapitulated, reviewed, and evaluated using the anatomical therapeutical chemical classification/defined daily doses (DDDs) and DU90\% methodologies. The results were statistically analyzed and compared before and after implementation of the national formulary.

Results: The quantity of drug use in DDD/1000 inhabitant per day was increased from 0.17 to 0.26 between 2013 and 2015 . The quality of drug use was also increased following a decrease in the number of drugs in the DU90\% segment. The percentage of drugs that adhered to the national formulary was $88.67 \%$; however, no significant difference was noted before and after the implementation of the national formulary.

Conclusion: The quantity, quality, and adherence of drug use to the national formulary was increased at the Depok city hospital after the implementation of the national formulary.

Keywords: Anatomical therapeutic chemical/defined daily doses, Depok hospital, Drug utilization, National formulary.

(c) 2018 The Authors. Published by Innovare Academic Sciences Pvt Ltd. This is an open access article under the CC BY license (http://creativecommons. org/licenses/by/4. 0/) DOI: http://dx.doi.org/10.22159/ijap.2018.v10s1.43

\section{INTRODUCTION}

National formulary was first applied as prescribing guidance for national health insurance in 2014 [1]. The national formulary comprises lists of essential drugs specific for health care and is widely used to promote rational pharmacotherapy [1]. Formularies are developed and implemented as management tools in primary health care and hospitals [2].

Respiratory disease is common in Indonesia. On the basis of basic health research report in 2013, the prevalence of respiratory disease in Indonesia is approximately $25 \%$, and infants are the most affected $(>35 \%)$. The high prevalence, as well as variations of this disease, can affect the pattern of drug use in health facilities. Respiratory diseases can be categorized as rhinitis, sinusitis, pharyngitis, laryngitis, epiglottis, and tonsillitis, based on the region affected; bronchitis, bronchiolitis, and pneumonia occur when the lower parts of the body are affected by the disease [3].

In 1981, the World Health Organization (WHO) recommended the anatomical therapeutic chemical/defined daily doses (ATC/DDDs) method as an international standard for drug utilization (DU) studies. The method was employed to evaluate the use of medicines and to detect any early signals of their irrational use. This method can be combined with the DU $90 \%$ method to identify the high use segment of medicine [4].

DU 90\% prescribing profiles have been proven valuable in general practice for assessing the overall prescribing quality. DU 90\% identifies drugs constituting $90 \%$ of the prescribed volume in DDDs and the adherence to the guidelines within this segment. It includes all the different drugs prescribed, and may, therefore, be useful for assessing the quality of drug prescription in hospitals $[4,5]$. The quality of prescribing drug and adherence to guidelines have been evaluated at different levels (hospital and primary care); a large diversity in the manner in which drugs are selected in the formulary and the methods used to develop and implement the formulary have been reported [2,5-7].

In the current study, we aimed to compare the quantity and quality of DU in patients with respiratory problems at a hospital in Indonesia before and after the implementation of the national formulary.

\section{METHODS}

This cross-sectional study was conducted in 2013 and 2015 at the Depok city hospital, in Indonesia. Data of drugs used at the hospital during the years 2013 and 2015 were obtained retrospectively from the pharmacy database. The survey included 11 types of respiratory diseases diagnosed at the hospital. Prescriptions for patients diagnosed with common cold, pharyngitis, tonsillitis, acute respiratory infection, bronchopneumonia, bronchitis, bronchiolitis, rhinitis, sinusitis, asthma, and bronchiectasis were included in this study. Prescriptions, treatment books, and patient data regarding respiratory diseases during the years 2013 and 2015 were reviewed and evaluated. The drugs included in the study were antihistamines, antimycobacterial, corticosteroids, nonsteroidal anti-inflammatory drugs, antipyretics, analgesics, respiratory drugs, medicines for cold and cough, and vitamins.

Data were collected and calculated as DDD/1000 inhabitants/day based on the ATC/DDD guidelines [3]. The total amount for each drug was converted to grams and calculated by multiplying the total number of drugs with the total amount in DDD units. The total amount of each drug in DDD units was calculated by dividing the total amount of drugs in grams by the DDD values of the drugs, as described on the WHO website. DDD is a technical unit based on the assumed average maintenance dose per day for a drug used for its main indication in adults. >1 DDD given to an adult patient per day could be viewed as an indication of overuse, and the data can be used as a signal for irrational use. 
Table 1: Prescriptions in 2013 and 2015 at Depok city hospital

\begin{tabular}{lll}
\hline Diagnosis & 2013 & 2015 \\
Rhinitis & 1269 & 1761 \\
Bronchitis & 1185 & 1585 \\
Asthma & 1054 & 993 \\
ARTI & 775 & 999 \\
Bronchopneumonia & 463 & 798 \\
Pharyngitis & 516 & 166 \\
Bronchiectasis & 296 & 347 \\
Tonsillitis & 49 & 34 \\
Common cold & 21 & 16 \\
Bronchiolitis & 4 & 0 \\
Sinusitis & 3 & 0 \\
Total prescription & 5635 & 6699 \\
\hline
\end{tabular}

Table 2: Population and drug consumption at Depok city hospital

\begin{tabular}{lll}
\hline Information & $\mathbf{2 0 1 3}$ & $\mathbf{2 0 1 5}$ \\
\hline Population (inhabitant) & $716,188,400$ & $742,230,420$ \\
Drug consumption (DDD) & $206,651.30$ & $231,056.6$ \\
Drug consumption & 0.16 & 0.25 \\
(DDD/1000 inhabitant/day) & & \\
\hline
\end{tabular}

DDD: Defined daily dose

Table 3: Pattern of drug use in 2013 and 2015 at Depok city hospital

\begin{tabular}{|c|c|c|c|c|}
\hline \multirow[t]{2}{*}{ No. } & \multirow[t]{2}{*}{$\begin{array}{l}\text { ATC/DDD } \\
\text { code }\end{array}$} & \multirow[t]{2}{*}{ Drug } & \multicolumn{2}{|c|}{$\begin{array}{l}\text { DDD/1000 } \\
\text { inhabitants per day }\end{array}$} \\
\hline & & & 2013 & 2015 \\
\hline 1 & R03AC02 & Salbutamol & 0.0707884 & 0.0917138 \\
\hline 2 & A11GA01 & Vitamin $\mathrm{C}$ & 0.0160150 & 0.0010532 \\
\hline 3 & R06AB02 & Chlorpheniramine maleate & 0.0135113 & 0.0023973 \\
\hline 4 & A11EA & Vitamin B complex & 0.0115919 & 0.0392870 \\
\hline 5 & B03BA01 & Cyanocobalamin & 0.0063092 & 0.0001867 \\
\hline 6 & $\mathrm{H} 02 \mathrm{AB} 02$ & Dexamethasone & 0.0046626 & 0.0030404 \\
\hline 7 & J04AC01 & Isoniazid & 0.0046417 & 0.0071698 \\
\hline 8 & A11DA01 & Thiamine & 0.0040855 & 0.0002398 \\
\hline 9 & R05CB06 & Ambroxol & 0.0037790 & 0.0109552 \\
\hline 10 & R03BA02 & Budesonide & 0.0033214 & 0.0024639 \\
\hline 11 & J01MA02 & Ciprofloxacin & 0.0032212 & 0.0021105 \\
\hline 12 & N02BE01 & Paracetamol & 0.0029292 & 0.0026081 \\
\hline 13 & H02AB0 4 & Methylprednisolone & 0.0028320 & 0.0038155 \\
\hline 14 & J04AB02 & Rifampicin & 0.0027357 & 0.0044885 \\
\hline 15 & R05CA03 & Glyceryl guaiacolate & 0.0026734 & 0.0012063 \\
\hline 16 & J01DB05 & Cefadroxil & 0.0020560 & 0.0014672 \\
\hline 17 & R06AX13 & Loratadine & 0.0017118 & 0.0001751 \\
\hline 18 & J01DD08 & Cefixime & 0.0015415 & 0.0037556 \\
\hline 19 & J01CR02 & Amoxicillin clavulanic & 0.0014199 & 0.0029817 \\
\hline 20 & J01CA04 & Amoxicillin & 0.0013778 & 0.0005841 \\
\hline 21 & R06AE07 & Cetirizine & 0.0013711 & 0.0326516 \\
\hline 22 & J04AK01 & Pyrazinamide & 0.0011073 & 0.0015260 \\
\hline 23 & A11HA02 & Pyridoxine & 0.0007112 & 0.0007270 \\
\hline 24 & R03DA04 & Theophylline & 0.0006964 & 0.0008053 \\
\hline 25 & M01AG01 & Mefenamic acid & 0.0006814 & 0.0006386 \\
\hline 26 & Н02АВ07 & Prednisone & 0.0005383 & 0.0004945 \\
\hline 27 & R05DA09 & Dextromethorphan & 0.0004301 & 0.0000009 \\
\hline 28 & M01AB55 & Kalium diclofenac & 0.0002883 & 0.0003025 \\
\hline 29 & M01AB55 & Natrium diclofenac & 0.0001892 & 0.0003065 \\
\hline 30 & H02АВ08 & Triamcinolone & 0.0001676 & 0.0155183 \\
\hline 31 & J04AK02 & Ethambutol & 0.0001414 & 0.0006967 \\
\hline 32 & J01FA01 & Erythromycin & 0.0001292 & 0.0000384 \\
\hline 33 & M01AE01 & Ibuprofen & 0.0001266 & 0.0000853 \\
\hline 34 & J01EE01 & Cotrimoxazole & 0.0001234 & 0.0000261 \\
\hline 35 & R05DA04 & Codeine & 0.0001003 & 0.0000857 \\
\hline 36 & J01BA02 & Thiamphenicol & 0.0000759 & 0.0000135 \\
\hline 37 & R01BA52 & Pseudoephedrine combination & 0.0000742 & 0.0017585 \\
\hline 38 & J01FA10 & Azithromycin & 0.0000698 & 0.0001055 \\
\hline
\end{tabular}

(Contd...)
Table 3: (Continued)

\begin{tabular}{lllll}
\hline \multirow{2}{*}{$\begin{array}{l}\text { No. } \\
\text { code }\end{array}$} & ATC/DDD & Drug & \multicolumn{2}{c}{$\begin{array}{l}\text { DDD/1000 } \\
\text { inhabitants per day }\end{array}$} \\
\cline { 4 - 5 } & & & $\mathbf{2 0 1 3}$ & $\mathbf{2 0 1 5}$ \\
\hline 39 & J01MA12 & Levofloxacin & 0.0000698 & 0.0000000 \\
40 & N02AX02 & Tramadol & 0.0000163 & 0.0000106 \\
41 & R05CB02 & Bromhexine & 0.0000056 & 0.0000539 \\
42 & J01BA01 & Chloramphenicol & 0.0000023 & 0.0000022 \\
43 & R01AD12 & Fluticasone furoate & 0 & 0.0158846 \\
44 & R03AC04 & Fenoterol HBr & 0 & 0.0000898 \\
45 & R03AK06 & Fluticasone propionate & 0 & 0.0015763 \\
46 & R03BA07 & Mometasone furoate & 0 & 0.0003772 \\
& & Total & 0.1683201 & 0.255475 \\
\hline p=0.865 DDD: Defined daily dose, ATC: Anatomical therapeutic chemical
\end{tabular}

The DDD/1000 inhabitants/year was calculated by dividing the total consumption in 1 year (DDD units) by the total number of visiting patients during the 1-year period divided by 1000; this can be divided by 365 to calculate the DDD/1000 patients/day. For example, the figure of 10 DDDs/1000 patients/day for amoxicillin (J01CA04) indicates that 10 out of 1000 patients (or 1\%) may have theoretically received a standard dose of amoxicillin ( 1 g every day).

Data regarding the number of patients and patterns of diseases were obtained from the total number of patients who visited the hospital and the disease report published by the district health office, respectively. Population data were obtained from the census data in 2013 and 2015.

Data on drug use were analyzed using descriptive statistics, and the most used drug segment was identified by the DU $90 \%$ method. The drugs were ranked by the volume of DDDs and those drugs accounted for $90 \%$ of the total volume, that is, the DU $90 \%$.

SPSS software was used for statistical analyses, with $\mathrm{p}<0.05$ considered significant. Non-parametric and parametric tests were performed to compare the quantity and quality of the drugs used. Adherence to prescription in 2015 was used for descriptive analyses.

\section{RESULTS}

Prescriptions were collected from patients who were diagnosed with 11 types of respiratory diseases using the International Statistical Classification of Disease and Related Health Problems, 42 and 46 types of drugs were used for the patients in 2013 and 2015, respectively (Tables 1-3). However, the ratios of drug consumption among the respiratory patients in 2013 and 2015 were 0.16 DDD/1000 inhabitants/day and $0.25 \mathrm{DDD} / 1000$ inhabitants/day, respectively $(\mathrm{p}>0.05)$.

As shown in Table 4, the DU $90 \%$ of 14 out of 42 types of drugs and 11 out of 46 drugs were obtained in 2013 and 2015, respectively. Drugs with the highest DU 90\% in 2013 were salbutamol (42.06\%), Vitamin C (9.51\%), and chlorpheniramine maleate $(8.03 \%)$ and in 2015 were salbutamol (35.90\%), Vitamin B complex (15.38\%), and cetirizine (12.78\%). No significant difference in DU $90 \%$ between the 2 years was noted $(\mathrm{p}>0.05)$.

It was found that the drug adherence of 47 types of drugs (88.67\%) and six types of drug in Depok city hospital were not included in national formulary. The drugs that were not included were thiamphenicol, kalium diclofenac, pseudoephedrine, glyceryl guaiacolate, ambroxol, and dextromethorphan.

\section{DISCUSSION}

The findings of the present study indicated the presence of variations in prescriptions for different respiratory problems. The formulary is 
Table 4: DU 90\% segment in Depok city hospital for the years 2013 and 2015

\begin{tabular}{|c|c|c|c|c|}
\hline \multirow[t]{2}{*}{ Rank } & \multicolumn{2}{|l|}{2013} & \multicolumn{2}{|l|}{2015} \\
\hline & Drug name & $\%$ & Drug name & $\%$ \\
\hline 1 & Salbutamol & 42.06 & Salbutamol & 35.90 \\
\hline 2 & Vitamin C & 9.51 & Vitamin B complex & 15.38 \\
\hline 3 & Chlorpheniramine maleate & 8.03 & Cetirizine & 12.78 \\
\hline 4 & Vitamin B complex & 6.89 & Fluticasone furoate & 6.22 \\
\hline 5 & Cyanocobalamin & 3.75 & Triamcinolone & 6.07 \\
\hline 6 & Dexamethasone & 2.77 & Ambroxol & 4.29 \\
\hline 7 & Isoniazid & 2.76 & Isoniazid & 2.81 \\
\hline 8 & Thiamine & 2.43 & Rifampicin & 1.76 \\
\hline 9 & Ambroxol & 2.25 & Methylprednisolone & 1.49 \\
\hline 10 & Budesonide & 1.97 & Cefixime & 1.47 \\
\hline 11 & Ciprofloxacin & 1.91 & Dexamethasone & 1.19 \\
\hline 12 & Paracetamol & 1.74 & & \\
\hline 13 & Methylprednisolone & 1.68 & & \\
\hline 14 & Rifampicin & 1.63 & & \\
\hline Total \% & & 89.37 & & 89.36 \\
\hline Total number of drugs & 42 & & 46 & \\
\hline
\end{tabular}

used to manage drug use and influence their applications in primary care and hospitals [1]. Depok city hospital is the intermediary health facility with the highest number of visiting patients in Depok city. This study showed that the population, rug consumption, and total number of prescriptions had increased over the years in Depok city (Tables 1 and 2).

Prescriptions for rhinitis were the highest at the hospital. Rhinitis is one of the most common atopic diseases and chronic disorders in childhood [8]. The International Study of Asthma and Allergies in Childhood Phase 3 reported that the prevalence rates of allergic rhinitis in Indonesia in children aged 6-7 years and 13-14 years were $3.6 \%$ and $6.4 \%$, respectively [9]. Several studies have evaluated the inflammatory properties of cetirizine in children and adults with allergic rhinitis [10]. In a previous study, children treated with cetirizine $(5 \mathrm{mg} /$ day for 4 weeks) demonstrated a significant reduction in inflammatory cell infiltrate [11]

The most highly prescribed drug at the Depok city hospital was salbutamol. Salbutamol is indicated for asthma and other conditions associated with reversible airway obstruction. Patients with severe acute asthma should be given high-flow oxygen (if available) and a short-acting beta 2 agonist through a large-volume spacer or salbutamol nebulizer [12]. Thus, salbutamol is the first line of treatment for asthma and was the most commonly used drug at the hospital in this study.

Fourteen drugs were included in the DU 90\% segment in the year 2013 and 11 in 2015, with Vitamin C being the most commonly prescribed drug. The prophylactic use of Vitamin C does not reduce the incidence of common cold but decreases the duration of the illness by 8\% [13]. Vitamin B12 was prescribed for respiratory problems and included in the DU $90 \%$ segment in the year 2013, in the current study. Vitamin B12 has been shown to maintain respiratory tract infections and decrease morbidity [14]. The corticosteroid dexamethasone was included among the DU $90 \%$ drugs used in 2013 and 2015. Corticosteroids have revolutionized the management of certain conditions, such as asthma and croup. In some conditions, such as bronchiolitis or cystic fibrosis, their use is controversial and not routinely recommended [15]. Fluticasone furoate, indicated as a prophylactic drug for allergic rhinitis and asthma, was not included in the DU90\% segment in 2013 but was included in 2015 [12].

\section{CONCLUSION}

In the present study, DU for respiratory problems was measured by calculating the DDD/1000 inhabitants/days and DU $90 \%$ at the
Depok city hospital in Indonesia. DDD/1000 inhabitants were found to be increased in 2015, and the quality of drug use was increased after implementation of the national formulary. The number of drugs in the DU 90\% segment was decreased from 11 to 14 types of drugs from 2013 to 2015, respectively. The adherence percentage of drugs in 2015 to the national formulary at the Depok city hospital was $88.67 \%$.

\section{CONFLICTS OF INTEREST}

All authors have none to declare.

\section{REFERENCES}

1. Indonesian Social Insurance Administration Organization. Republic of Indonesia Law Number 24 of 2011. Indonesia: Indonesian Social Insurance Administration Organization; 2011.

2. Plet HT, Hallas J, Kjeldsen LJ. Adherence to hospital drug formularies and cost of drugs in hospitals in Denmark. Eur J Clin Pharmacol 2013;69:1837-43.

3. Ministry of Health. Pharmaceutical Care for Respiratory Tract Infections. Jakarta: Ministry of Health, Republic of Indonesia; 2005.

4. World Health Organization Collaborating Centre for Drug Statistics Methodology. Guidelines for ATC Classification and DDD Assignment. In: Guidelines for ATC Classification and DDD Assignment, Oslo, Norway. Oslo: World Health Organization Collaborating Centre for Drug Statistics Methodology; 2016.

5. Wettermark B, Haglund K, Gustafsson LL, Persson PM, Bergman U. A study of adherence to drug recommendations by providing feedback of outpatient prescribing patterns to hospital specialists. Pharmacoepidemiol Drug Saf 2005; 14:579-88.

6. Catić T, Begović B. Outpatient antihypertensive drug utilization in canton Sarajevo during five years period (2004-2008) and adherence to treatment guidelines assessment. Bosn J Basic Med Sci 2011;11:97-102.

7. Horvat O, Mijatović V, Čalasan J, Sabo A. Outpatient utilization of non-steroidal anti-inflammatory drugs in three largest municipalities in South Backa district. SRPSKI Arh Celok Lek 2012;140:339-43.

8. Sastra S, Irsa L, Loebis MS, Evalina R. Number of siblings and allergic rhinitis in children. Paediatr Indones 2016;56:1-7.

9. Aït-Khaled N, Pearce N, Anderson HR, Ellwood P, Montefort S, Shah J, et al. Global map of the prevalence of symptoms of rhinoconjunctivitis in children: the international study of asthma and allergies in childhood (Isaac) phase three. Allergy 2009;64:123-48.

10. Zhang L, Cheng L, Hong J. The clinical use of cetirizine in the treatment of allergic rhinitis. Pharmacology 2013;92:14-25.

11. Ciprandi G, Tosca M, Ricca V, Passalacqua G, Fregonese L, Fasce L, et al. Cetirizine treatment of allergic cough in children with pollen allergy. Allergy 1997;52:752-4.

12. British Medical Association. BMJ Group and the royal 
pharmaceutical. Committee, joint formulary. In: British National Formulary 68; 2014 Society of Great Britain. England: British Medical Association; 2014.

13. Fashner J, Ericson K, Werner S. St Joseph and family medicine. Treatment of the common cold in children and adults. Am Fam Phys 2012;86:153-9.
14. Strand TA, Taneja S, Bhandari N, Refsum H, Ueland PM, Bahl R, et al. Folate, but not Vitamin B-12 status, predicts respiratory morbidity in North Indian children. Am J Clin Nutr 2007;7:139-44

15. de Benedictis FM, Bush A. Corticosteroids in respiratory diseases in children. Am J Respir Crit Care Med 2012;185:12-23. 